\title{
Spatial and Temporal Variation Characteristics of Heatwaves in Recent Decades over China
}

\author{
Jinping Liu $\left.{ }^{1}{ }^{(}\right)$, Yanqun Ren ${ }^{1, *}$, Hui Tao $^{2}$ and Masoud Jafari Shalamzari ${ }^{3}$ \\ 1 College of Surveying and Geo-Informatics, North China University of Water Resources and Electric Power, \\ Zhengzhou 450046, China; liujp@radi.ac.cn \\ 2 State Key Laboratory of Desert and Oasis Ecology, Xinjiang Institute of Ecology and Geography, \\ Chinese Academy of Sciences, Urumqi 830011, China; taohui@ms.xjb.ac.cn \\ 3 Key Laboratory of Digital Earth Science, Aerospace Information Research Institute, University of Chinese \\ Academy of Sciences, Beijing 100094, China; msd_jafari@alumni.ut.ac.ir \\ * Correspondence: renyanqun@ncwu.edu.cn
}

Citation: Liu, J.; Ren, Y.; Tao, H.; Shalamzari, M.J. Spatial and Temporal Variation Characteristics of Heatwaves in Recent Decades over China. Remote Sens. 2021, 13, 3824. https://doi.org/10.3390/rs13193824

Academic Editor: Costas Varotsos

Received: 23 August 2021

Accepted: 20 September 2021

Published: 24 September 2021

Publisher's Note: MDPI stays neutral with regard to jurisdictional claims in published maps and institutional affiliations.

Copyright: (c) 2021 by the authors. Licensee MDPI, Basel, Switzerland. This article is an open access article distributed under the terms and conditions of the Creative Commons Attribution (CC BY) license (https:// creativecommons.org/licenses/by/ $4.0 /)$.

\begin{abstract}
Global warming and rapid socioeconomic development increased the risk of regional and global disasters. Particularly in China, annual heatwaves (HWs) caused many fatalities and substantial property damage, with an increasing trend. Therefore, it is of great scientific value and practical importance to analyze the spatiotemporal changes of HW in China for the sustainable development of regional socioeconomic and disaster risk management. In this study, based on gridded maximum temperature product and specific humidity dataset, an HW evaluation algorithm, considering the impact of humidity on the human body and the characteristics of HW in China, was employed to generate daily HW state at light, moderate, and severe levels for the period 1979-2018. Consequently, the regional differences at three HW levels were revealed, and the changing trend of HW onset, termination, and duration in each subregion was analyzed. The results show that in the three levels, the frequency and duration of HW in China had a significant increasing trend, generally characterized by the advancement of HW onset and the postponement of HW termination. The HW influence at light, moderate and severe levels decreased gradually, with the light level occurring the earliest and terminating the latest. Among the seven subregions, the largest HW frequency happened to be mainly in XJ (Xinjiang), SC (Southern China), and NC (Northern China), while the variations of HW onset and termination had noticeable regional differences at the three levels. The findings presented in this study can provide the essential scientific and technological support for national and regional disaster prevention mitigation and adaptation to extreme climate events.
\end{abstract}

Keywords: heatwave; frequency; onset and termination; heatwave level; regional difference

\section{Introduction}

In the context of global warming, the socioeconomics of China faces four severe challenges, the most severe of which being the intense, extreme high-temperature events with an increasing trend [1,2]. It is generally believed that heatwave (HW) is caused by continuous high temperatures, a weather disaster in which people, animals, and plants cannot adapt to the environmental conditions [3,4]. Early studies showed that the frequency and duration of HW events in most regions of the world are on the rise [5-8]. The HW poses a severe threat to human survival, socioeconomic development, water resources, and the environment [9-13]. In view of the severe impact of HW events, much attention from researchers and the public community was focused on related disciplines in recent decades [14-16].

Since the 1960s, the frequency, intensity, and duration of HW in the US evidently increased [6,17]. Europe experienced severe heatwaves in June and August of 2003, July of 2006, July-August of 2010 and 2018, and even an unprecedented heatwave in JuneJuly 2019 [18]. Severe heatwaves were experienced in China since the beginning of the 
21st century. For example, long-term scorching hot weather broke the hottest summer record in Shanghai city in more than 50 years in August $2003[19,20]$. In the summer of 2013, high temperatures in southeastern China broke the 141-year record. Among the southeastern regions, in Pudong New Area with only 1430 km², China's engine of economic and social development, the high temperatures killed 1755 people [21]. Simultaneously, the vast majority of Zhejiang province also experienced daily high temperatures exceeding $42{ }^{\circ} \mathrm{C}$ [22]. Based on 534 national meteorological stations over China, Ding and Ke [23] found that the HW occurred more frequently since the 1990s. Also, using observations from 753 national stations in China, Ye et al. [24] showed that the summer HW significantly strengthened, indicating an expansion in the area since the 1990s. Therefore, investigating the spatiotemporal characteristics of HWs in China is of considerable importance and significance [25].

Although much effort was made to understand HWs around the world in recent decades, there is still no standard agreed upon for the definition of an HW. For example, the World Meteorological Organization (WMO) suggests that the weather with daily maximum temperature (hereafter, maximum temperature is referred to as MAXT) of greater than $32{ }^{\circ} \mathrm{C}$ and lasting for more than three consecutive days could be regarded as an HW; The Royal Netherlands Meteorological Institute (KNMI) regards the weather process with daily MAXT greater than $25^{\circ} \mathrm{C}$ lasting for more than five consecutive days with at least three days with MAXT greater than $30^{\circ} \mathrm{C}$ to be an HW. In China, the MAXT of $35^{\circ} \mathrm{C}$ lasting for more than three days was defined as an HW by China Meteorological Administration (CMA). However, the mentioned criterion was not suitable for complex terrain and diverse climatic types (e.g., China). Therefore, multiple HW evaluation methods were proposed around the world, most of which involving the combination of one or two factors of MAXT, dew point temperature, relative humidity (RH), and water vapor pressure [26-31]. Huang et al. [32] summarized these definitions and the related research around the HW and proposed that comprehensive meteorological indicators should be used to evaluate human comfort. Merging this viewpoint with the criterion adopted in China, Huang et al. [32] proposed a calculation model for evaluating HW for China, which was employed in this study.

Most of the previous research around HW in China solely used maximum temperature at the site scale, which may introduce a large amount of errors into the HW evaluation results due to insufficient consideration of variables (e.g., humidity) and spatial interpolation, resulting in high uncertainty in the conclusions. It may cause problems in the delineation of light, moderate, and severe HW levels in China. This study focuses on revealing the changing trends in HW characteristics on different levels in China, including four main objectives: (1) generating a daily HW assessment dataset for China; (2) investigating the spatial distribution and change trend of high-temperature days (HTD); (3) analyzing the spatiotemporal variation of HW frequency at the light, moderate, and severe levels in seven subregions in China, and (4) clarifying the changes in HW onset, termination, and duration in different subregions. The rest of this paper is organized as follows: Section 2 introduces the study area, datasets, HW calculation method, and the associated key parameters (i.e., HW onset, termination, and duration). Section 3 focuses on the results of HTD and HW spatiotemporal characteristics at the different levels. Section 4 provides a discussion for results presented in this study. A summary and conclusions are given in Section 5. Additionally, all abbreviations and corresponding full names presented in this study were illustrated in Table A1 to better the reader's understanding.

\section{Materials and Methods}

\subsection{Study Area}

The diverse topography ( $-154-8848 \mathrm{~m}$ ) leads to a variety of climates in China. To better explain the spatial differences of heatwave intensity changes in China, a similar geographical division method proposed by Guo et al. [33] was adopted in this study. Besides elevation, mountain ranges [34], and the annual precipitation isohyet [35], the 
climate zoning derived from Resource and Environment Science and Data Center (RESDC, http:/ / www.resdc.cn/, accessed on 25 January 2021) is also taken into account in some regions (e.g., Xinjiang and Qinghai-Tibetan Plateau). Therefore, China is separated into seven subregions as illustrated in Figure 1a, with spatial distributions of multiyear average of the maximum temperature (Figure 1b) and relative humidity (Figure 1c) from May to September; namely, (I) Xinjiang (XJ) region, where the range of the maximum temperature (MAXT) and relative humidity (RH) is $4.2-37.8^{\circ} \mathrm{C}$ and $0.11-0.84$ from May to September during 1979-2018, respectively; (II) Qinghai-Tibetan Plateau (QTP), also known as the third pole of the world with an average elevation about $4500 \mathrm{~m}$, where the range of MAXT and $\mathrm{RH}$ is $-1.8-28.2{ }^{\circ} \mathrm{C}$ and $0.13-1.00$, respectively; (III) Northwest (NW), divided by $400 \mathrm{~mm}$ annual precipitation isohyet, where the range of MAXT and $\mathrm{RH}$ is $11.9-30.8^{\circ} \mathrm{C}$ and 0.18-0.76, respectively; (IV) Northeast (NE), located in the north of the Yan mountain, where the range of MAXT and RH of $17.9-27.4{ }^{\circ} \mathrm{C}$ and $0.35-0.68$, respectively; (V) Northern China (NC), located in the north of Qinling Mountains-Huai River line, where the range of MAXT and RH is $18.5-30.2{ }^{\circ} \mathrm{C}$ and $0.32-0.84$, respectively; (VI) Southwest (SW), bounded by the Ta-pa Mountains and Wulingshan mountains to the north and east, respectively, where the range of MAXT and RH is $8.1-36.6^{\circ} \mathrm{C}$ and $0.25-0.99$, respectively; (VII) Southern China (SC), located in south of the Nanling mountains and southeast of the Wuyi Mountains, where the range of MAXT and RH is $9.4-35.4{ }^{\circ} \mathrm{C}$ and $0.38-0.94$, respectively. Specifically, more detailed information on these seven subregions is illustrated in Table 1.

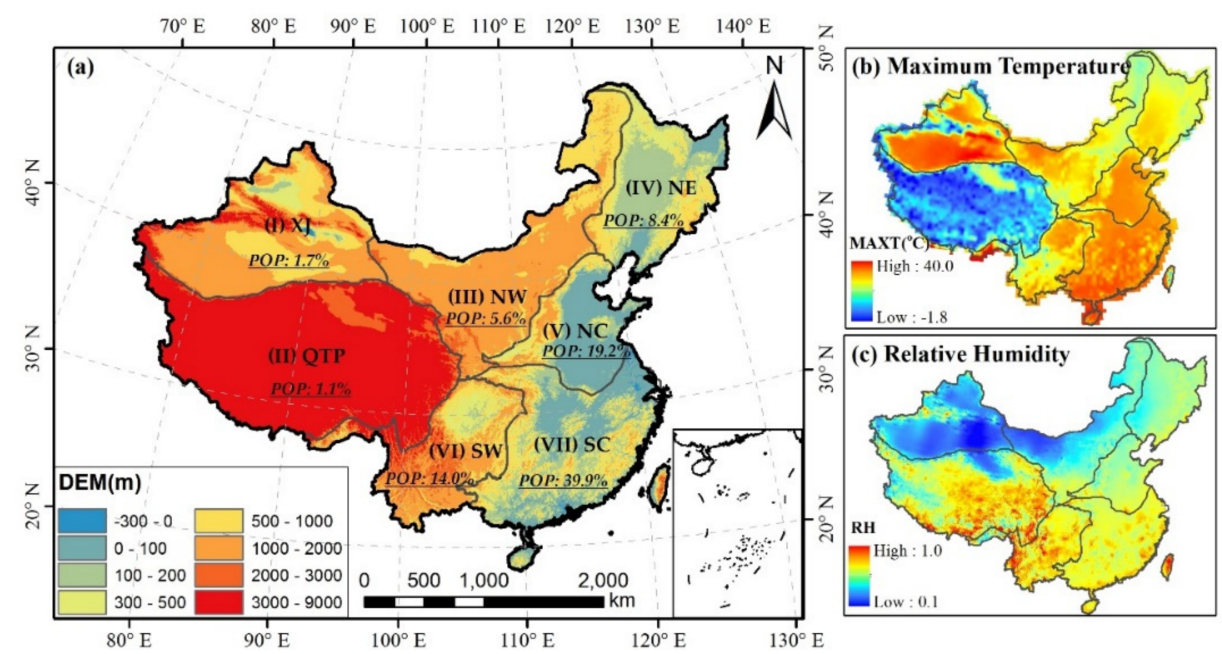

Figure 1. Overview of study area. (a) Topographic features of China and subregional divisions: (I) Xinjiang (XJ), (II) Qinghai-Tibetan Plateau (QTP), (III) Northwest (NW), (IV) Northeast (NE), (V) North China (NC), (VI) Southwest (SW), and (VII) South China (SC); POP is ratio between local and total population of China. (b) Maximum temperature from May to September during 1979-2018. (c) Relative humidity from May to September during 1979-2018.

Table 1. Average of max temperature (TMAX) and relative humidity (RH), and predominant climate in seven subregions of China.

\begin{tabular}{cccc}
\hline Subregion & TMAX Average & RH Average & Predominant Climate \\
\hline (I) $\mathrm{XJ}$ & $26.4^{\circ} \mathrm{C}$ & 0.29 & Temperate continental climate \\
(II) QTP & $12.8^{\circ} \mathrm{C}$ & 0.58 & Subfrigid climate \\
(III) NW & $24.1^{\circ} \mathrm{C}$ & 0.39 & Arid and semiarid climate \\
(IV) NE & $23.8^{\circ} \mathrm{C}$ & 0.48 & Humid and semihumid climate \\
(V) NC & $28.0^{\circ} \mathrm{C}$ & 0.52 & Semihumid climate \\
(VI) SW & $25.2^{\circ} \mathrm{C}$ & 0.65 & Humid climate \\
(VII) SC & $29.3^{\circ} \mathrm{C}$ & 0.61 & Humid climate \\
\hline
\end{tabular}


The population of XJ, QTP, NW, NE, NC, SW, and SC accounts for $1.7 \%, 1.1 \%, 5.6 \%$, $8.4 \%, 19.2 \%, 14.0 \%$, and $39.9 \%$ of the total population of China, respectively, according to the spatial distribution of the population of China in 2015 derived from RESDC. This study does not make a quantitative analysis of the population's exposure to HWs due to the length limit and focalization of this study. The population data are provided to assist the readers in having a preliminary understanding of the impact of HWs on populations in different subregions.

\subsection{Data Utilized and Processing}

To calculate the HWs' data, this study derived the MAXT and Specific Humidity (SH) on a daily timescale from the National Meteorological Information Center (NMIC) and National Tibetan Plateau/Third Pole Environment Data Center (TPDC). The MAXT was gridded using the recorded values from approximately 2400 meteorological stations based on the Thin Plate Spline (TPS) method. The MAXT exhibited an average deviation of $\pm 0.2{ }^{\circ} \mathrm{C}$ and the RMSE of $0.25^{\circ} \mathrm{C}$ with the spatial resolution of 0.5 degrees when compared to that of the independent gauge observations in the validation stage. The $\mathrm{SH}$ was generated during the period 1979 to 2018 by merging the observations from NMIC, Tropical Rainfall Monitoring Mission (TRMM) 3B42 precipitation analysis data, the downward shortwave radiation of Global Energy and Water Exchanges-Surface Radiation Budget (GEWEX-SRB) and Global Land Data Assimilation System (GLDAS), the surface pressure of Modern-Era Retrospective analysis for Research and Applications (MERRA) and GLDAS, and wind, air temperature, relative humidity from GLDAS, at the spatial resolution of 0.1 degrees [36-38]. Given the consistency with SH and spatial continuity, the MAXT was spatially aggregated to a 0.1 -degree resolution using the bilinear interpolation.

The China Meteorological Forcing Dataset solely provides $\mathrm{SH}$, yet $\mathrm{RH}$ is required to evaluate HW as a valuable proxy for health impact studies. In this study, the RH with a spatiotemporal resolution of 0.1 degrees/daily over China was calculated based on the $\mathrm{SH}$ throughout the study period using the humidity package in R (https:/ / rdrr.io/cran/ humidity/, accessed on 16 January 2021). For a more detailed description of the applied algorithm for converting SH to RH, please refer to Murray [39] and Shaman and Kohn [40].

In addition, Figure $1 b, c$ and description related to the maximum temperature and relative humidity were mapped, and they were provided based on the datasets of MAXT and $\mathrm{RH}$, respectively.

\subsection{Methodology}

\subsubsection{Heatwave Index and Levels}

At present, the standard of issuing a warning based on temperature extremes in China is set at daily MAXT of higher than $35{ }^{\circ} \mathrm{C}$, as compared with $32{ }^{\circ} \mathrm{C}$ recommended by the World Meteorological Organization (WMO). According to Huang et al. [32], the critical temperature of $33^{\circ} \mathrm{C}$ is used as the threshold to distinguish HTD by combining the Chinese and WMO criteria. By taking high temperatures as the signal into account and with respect to the duration of the phase, Huang et al. [32] introduced the heatwave index (HWI), which not only includes temperature and relative humidity, but also accounts for their impact on human health. The index can be calculated as Equation (1):

$$
H W I_{i}=1.2\left(E_{T}-E_{T}^{\prime}\right)+0.35 \sum_{i=1}^{N-1} \frac{1}{n d_{i}} \times\left(E_{T i}-E_{T}^{\prime}\right)+0.15 \sum_{i=1}^{N-1} \frac{1}{n d_{i}}+1
$$

in which $E_{T}$ is the heat index of the current day representing human comfort, $E^{\prime}{ }_{T}$ denotes the critical heat value with higher values indicating the sense of heat, $E_{T i}$ is the heat index of the $i$-th day before the current day, $n d_{i}$ represents the number of days from the $i$-th day to the current day. Please note that the $i$-th day is before the current day. For example, if the onset date of this heatwave is 5 August 2018 and the current day is 9 August 2018, the value of $n d_{i}$ is $4,3,2,1$, respectively, with the varying of $i$ in the range of 1 to 4 . $N$ is the 
duration of a heatwave process, for example, the value of $\mathrm{N}$ is 11 if a heatwave starts on 5 August 2018 and ends on 15 August 2018.

Thom [41] proposed the heat index $E_{T}$, which mainly considered the influence of temperature and $R H$ on human comfort. It can be expressed by Equation (2):

$$
E_{T}=1.8 T_{a}-0.55\left(1.8 T_{a}-26\right) \times(1-R H)+32
$$

in which $T_{a}$ is the maximum ambient temperature in Celsius degree $\left({ }^{\circ} \mathrm{C}\right)$, and $R H$ represents daily relative humidity at the range of $0-1$.

Due to the introduction of $\mathrm{RH}$ into the equation, $E_{T}$ is reasonably useful to characterize the sense of abnormal humidity for the human body at high temperatures and relative humidity. However, the calculated $E_{T}$ was typically lower in northern China, given its high temperatures and dry weather, which can also seriously impact human health [32]. Therefore, the temperature is the dominant factor affecting the human body's comfort, particularly at lower $R H$. Under these circumstances, it was assumed that the influence of RHs less than 0.6 on the human body is equivalent. Therefore, Huang et al. [32] adjusted the $E_{T}$ calculation as a stage function of $R H$; that is, at $R H<0.6$, it is treated as a constant of 0.6. In this manner, the correct $E_{T}$ can be obtained for hot and dry weather in northern China. The adjusted calculation formula of $E_{T}$ can be expressed as follows:

$$
E_{T}\left\{\begin{array}{cc}
1.8 T_{a}-0.55\left(1.8 T_{a}-26\right) \times(1-0.6)+32 & R H \leq 0.6 \\
1.8 T_{a}-0.55\left(1.8 T_{a}-26\right) \times(1-R H)+32 & R H>0.6
\end{array}\right.
$$

in which $T_{a}$ and $R H$ are the same as previously established.

The $E^{\prime}{ }_{T}$ critical heat value is used to judge whether it is high temperature or hot weather. When ET is greater than $E_{T}^{\prime}$, it means that the given day reached the hightemperature state, and HWI should be calculated. China has a large area with various climates, with different sensitivities among the population to the same temperature. Therefore, the determination $E_{T}^{\prime}$ should make allowance for the regional differences instead of a united nationwide approach. To be specific, the local long-term daily meteorological data are firstly used to calculate the $E T$ (regarded as $\mathrm{ET}_{33}$ ) with the MAXT greater than $33^{\circ} \mathrm{C}$ [32]. Then, the $\mathrm{ET}_{33}$ series is sorted in ascending order. Finally, according to Huang et al. [32], the 50th quantile is selected as the local $E^{\prime} T$. The quantile can be calculated by the empirical method as Equations (4)-(6):

$$
\begin{gathered}
\hat{Q}_{i}(p)=(1-\gamma) X_{j}+\gamma X_{j+1} \\
j=\operatorname{int}\left[p n+\frac{1+p}{3}\right] \\
\gamma=p n+\frac{1+p}{3}-j
\end{gathered}
$$

in which $\hat{Q}_{i}(p)$ is the $i$ th quantile, $X$ denotes the sample sequence of the $\mathrm{ET}_{33}$ in ascending order, $p$ is the $50 \%$ quantile, $n$ is the length of $\mathrm{ET}_{33}$ series, $j$ is the $j$ th $\mathrm{ET}_{33}, \gamma$ is the weight of the $(j+1)$ th number.

To measure the impact of different meteorological conditions on socioeconomic conditions and human health, the $H W$ level was classified into light $H W$, moderate $H W$, and severe $H W$ based on the HWI. The classification ranges are provided in Table 2 [32]. According to Huang et al. [32], these classification thresholds are primarily determined by the correlation between heatstroke, the death toll, and HWI in different regions of China, as well as the frequency of heatwaves in historical events. In general, the occurrence of a heatwave is always accompanied by heatstroke. With the increase of extremely high temperatures and humidity, the heatwave level and the number of heatstrokes increased gradually. All levels of heatwaves, especially moderate and severe heatwaves, appear in a relatively long period of the high-temperature process (beyond three days). 
Table 2. Ranges used for $H W$ level classification.

\begin{tabular}{cc}
\hline Level & Classification Criteria \\
\hline Light & $2.8 \leq H W I<6.5$ \\
Moderate & $6.5 \leq H W I<10.5$ \\
Severe & $H W I \geq 10.5$ \\
\hline
\end{tabular}

\subsubsection{Calculation of Seasonal HW Parameters}

Generally, a given $H W$ can bring different damage at different times. For example, an $H W$ in late spring and early summer can cause higher mortality than in midsummer, mainly because of the inability of the human body to promptly adapt to the new condition during a sudden $H W$. It may result in more serious harm to the human body, animals, and plants. Therefore, it is important to determine the onset and the termination of heatwave (HWO and $H W T$, respectively) and to analyze the time trend since they are of great importance for determining extreme weather conditions and the HWs impact on human comfort.

To derive the onset and termination of HWs in each year, the method described as Equations (7) and (8) was adopted in this study.

$$
\begin{array}{cc}
H W O=\operatorname{First}\left\{\operatorname{True}\left(H W_{i}\right)\right\} & i=1 \cdots 365 / 366 \\
H W T=\operatorname{Last}\left\{\operatorname{True}\left(H W_{i}\right)\right\} & i=1 \cdots 365 / 366
\end{array}
$$

in which True is a function to judge whether $H W_{i}$ reaches the light, moderate, or severe levels. Accordingly, the heatwave duration (HWD) can be calculated as Equation (9):

$$
H W D=H W T-H W O
$$

The procedure to calculate $H W O, H W T$, and $H W D$ was applied to each year from 1979 to 2018 , and the results are given in Section 3.3.

\section{Results and Discussion}

\subsection{Spatial Distribution and Variations of High-Temperature Days}

As shown in Figure 2, the annual mean HTDs ranged from 0 to 185 days during the study period, in which the HTDs over XJ, SC, and NC were relatively higher than that in NW, SW, NE, and QTP. Especially in the Tarim Basin of XJ, the HTDs were more than 50 days, while in the QTP, the HTDs were almost zero. In most areas of the northeast and northwest, the number of days with high temperatures was fewer than 14 days. There was an area with extremely high value to the west of the southwest sector (i.e., Southeast QTP). To analyze the variation characteristics of HTDs, the interannual variation of HTDs over seven subregions of China was calculated, as shown in Figure 3. The HTDs had an increasing trend in China and associated subregions during the study period at the significance level of 0.05 , except NE. It demonstrates that extremely high temperatures were on the rise in China over the past few decades as a result of global warming. Among the seven subregions, the QTP had the slightest HTDs rising rate $(0.01 \mathrm{~d} /$ decade). However, it may cause more severe impacts than in other regions, which directly or potentially impact the climate and environment of the surrounding regions, even that of the globe. Conversely, the region with the fastest increasing rate in terms of HTDs was SC, with a value of $4.86 \mathrm{~d}$ /decade, implying the highest population exposure to extremely high temperatures.

Figure 4 illustrated the spatial change trend and the associated significance level of HTDs over China during 1979-2018. Most of China experienced a significant increase in HTDs at the level of 0.05. However, most QTP and northeast of NE experienced no trend and a nonsignificant decreasing trend, respectively. As shown in Figure 4a, although HTDs in most NE showed an increasing trend, it was not statistically significant (Figure $4 \mathrm{~b}$ ). Therefore, it indicated that only the QTP and NE were less affected by the extremely high temperatures in China. In contrast, the most significant changes appeared in XJ, SC, and northern SW, with the increasing rate in HTDs exceeding $5.0 \mathrm{~d} /$ decade. In XJ, SC, and SW, 
approximately $94.7 \%, 98.6 \%$, and $77.7 \%$ of the pixels had an increasing trend in HTDs, in which $65.7 \%, 90.7 \%$, and $50.1 \%$ of the pixels were significant, respectively. For NW and NC, the increasing HTDs rate was generally below $5.0 \mathrm{~d} /$ decade. Sum $97.3 \%$ and $99.5 \%$ of the pixels experienced an increasing trend, in which $63.6 \%$ and $71.6 \%$ pixels were significant. Overall, the interannual variability of HTDs in the north and south has great differences.

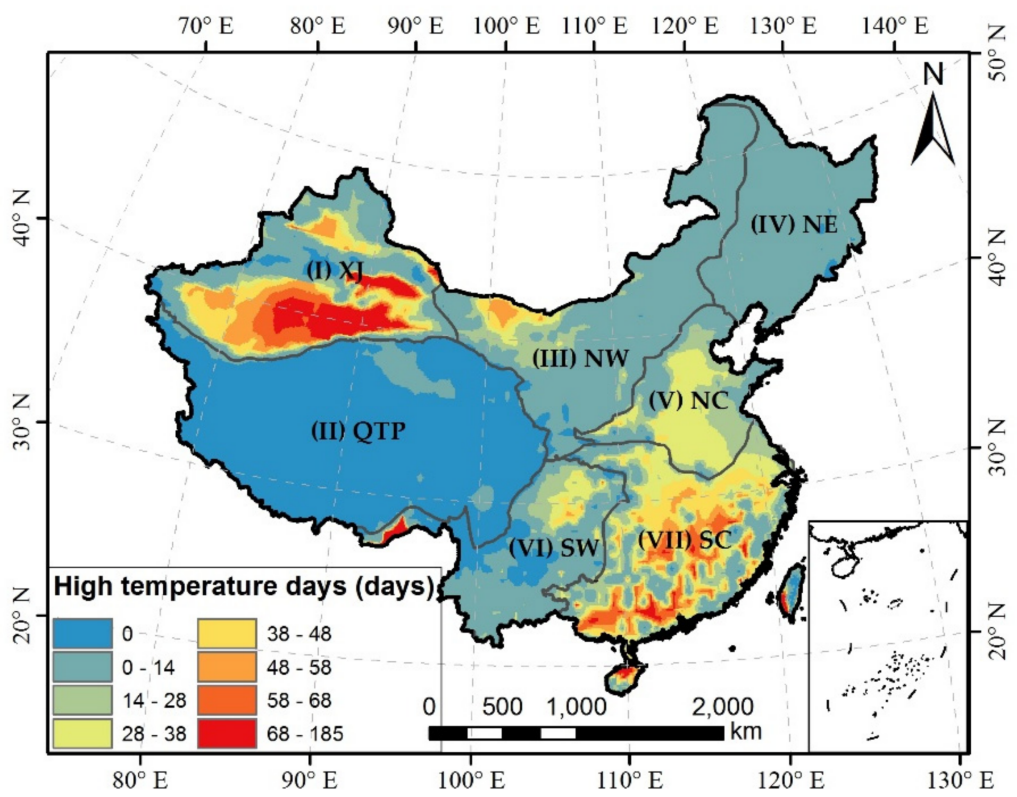

Figure 2. Spatial distribution of annual mean high-temperature days over China during 1979-2018.
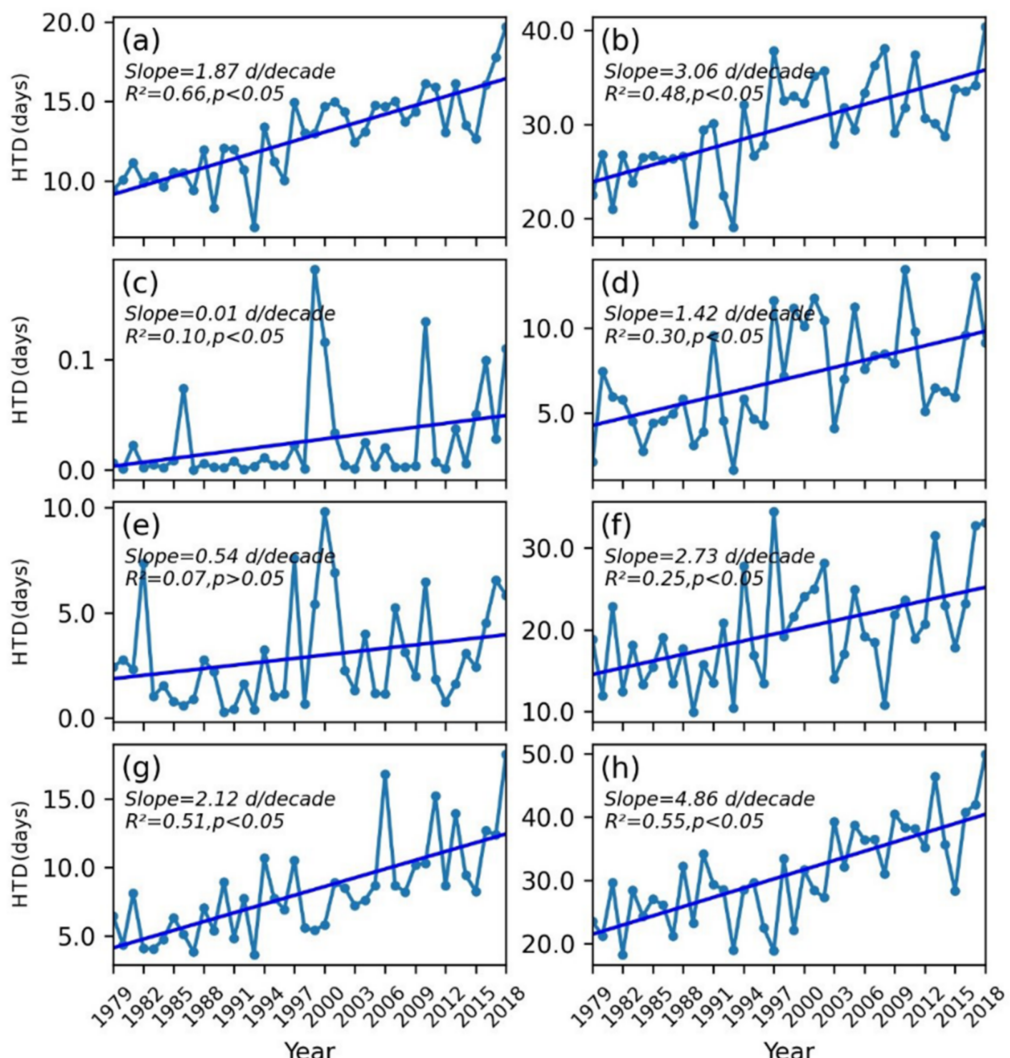

Figure 3. Temporal changes of annual high-temperature days (HTDs) over China and different subregions during 1979-2018. (a) China, (b) XJ, (c) QTP, (d) NW, (e) NE, (f) NC, (g) SW, and (h) SC. Blue solid line is change trend in HTDs. 

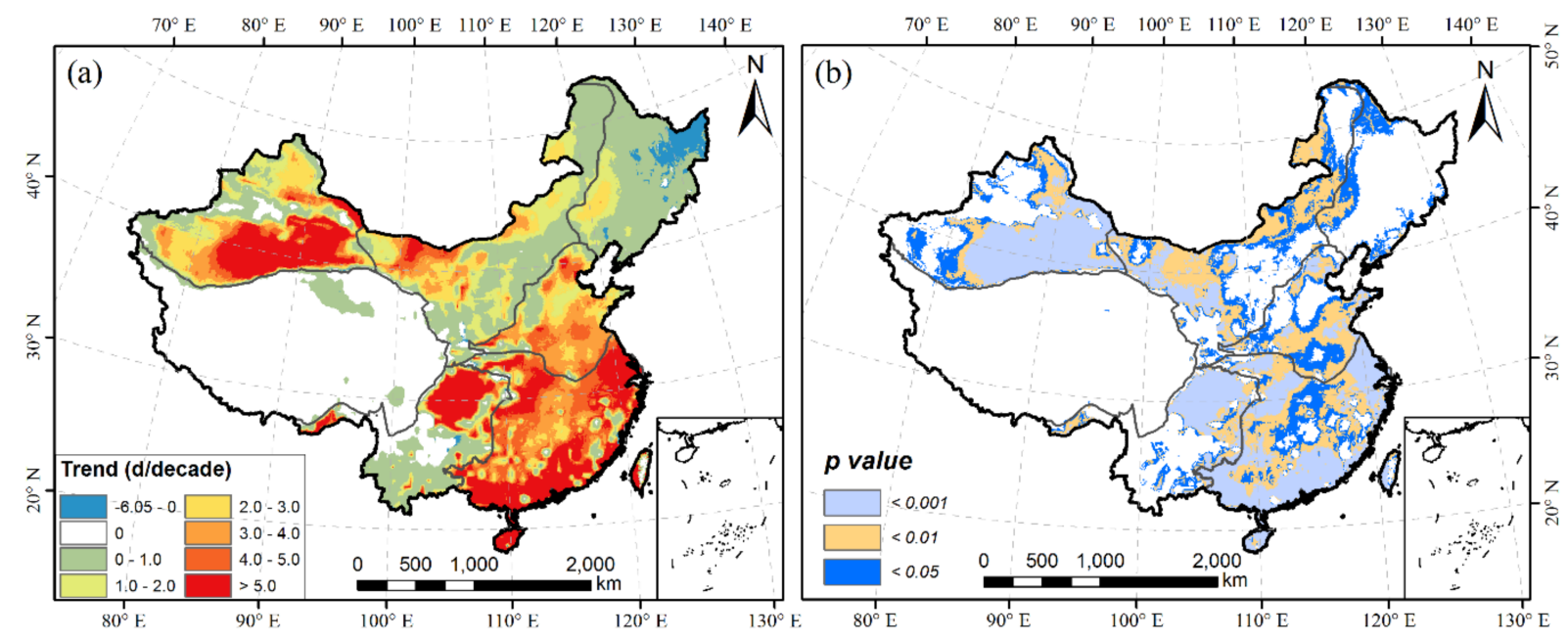

Figure 4. Changes of HTDs over China during the period 1979-2018. (a) Change trend; (b) corresponding statistical $p$ values for HTDs, in which $p<0.001, p<0.01$, and $p<0.05$ represents significant corresponding change trend at level of $0.001,0.01$, and 0.05 , respectively.

\subsection{Variations of Heatwave Frequency}

According to the definition of heatwave, high temperature does not mean that a heatwave is bound to occur. Besides high temperature, reaching to the criteria of heatwave also has a demand for relative humidity to some extent. To clarify the difference between HTD and heatwave frequency, the investigation of heatwave frequency is conducted in this section.

The spatial distribution of heatwave frequency at different levels (i.e., severe, moderate, and light) is illustrated in Figure 5. The heatwave frequency in this study is on the annual scale, including total heatwave frequency (THWF), severe heatwave frequency (SHWF), moderate heatwave frequency (MHWF), and light heatwave frequency (LHWF). The THWF, representing the number of all heatwave events in one year for a specific location, is the sum of SHWF, MHWF, and LHWF. For the THWF (Figure 5a), the spatial pattern was similar to that of the average annual HTDs (see Figure 2), but the THWF was much smaller than HTDs. It indicates that only a part of high temperatures can reach a HW level, which is because HWs are the joint and cumulative effect of high temperatures and humid weather. For severe heatwaves (Figure 5b), only a small part of XJ had a 5-10 days duration, while it was less than five days in other regions, especially in the whole QTP with no heatwaves. Compared with that of the severe heatwave, the moderate heatwave (Figure 5c) and light heatwave (Figure 5d) classes gradually expanded and gained higher frequencies. The light and moderate heatwaves began to appear in the northern XJ. With the intensification of global warming, severe heatwaves are likely to occur in the future, and the area under the influence of heatwaves will expand to a certain extent.

Figure 6 illustrated the variations in heatwave frequency at different levels. The THWF, LHWF, MHWF, and SHWF all exhibited an increasing trend over the seven subregions. However, as for the change rate and significance, there were great differences among different subregions. Regional variations of HWF over QTP were not analyzed here due to extremely small change rates and nonsignificance. For the changing trend of THWF, almost all the subregions were significant at the level of 0.05 , while it was relatively larger over SC and XJ than other subregions, with a change rate of $2.88 \mathrm{~d} /$ decade and $2.26 \mathrm{~d} /$ decade, respectively. However, it was not significant and gained a minimum $(0.21 \mathrm{~d} /$ decade $)$ over NE among six other subregions for the changes in the trend of THWF. In terms of LHWF, MHWF, and SHWF, their change rates were gradually decreasing. However, the SHWF was larger than LHWF in terms of change rate over XJ, which indicated that the change of HWF over other subregions was relatively milder compared with that of XJ because it gave people a chance to be adapted to the change from LHWF to SHWF. Over NE, LHWF, 
and MHWF fluctuated considerably over the past decades, which led to a nonsignificant increasing trend, while the change rate of SHWF had a very small but significant increasing trend during the entire study period.
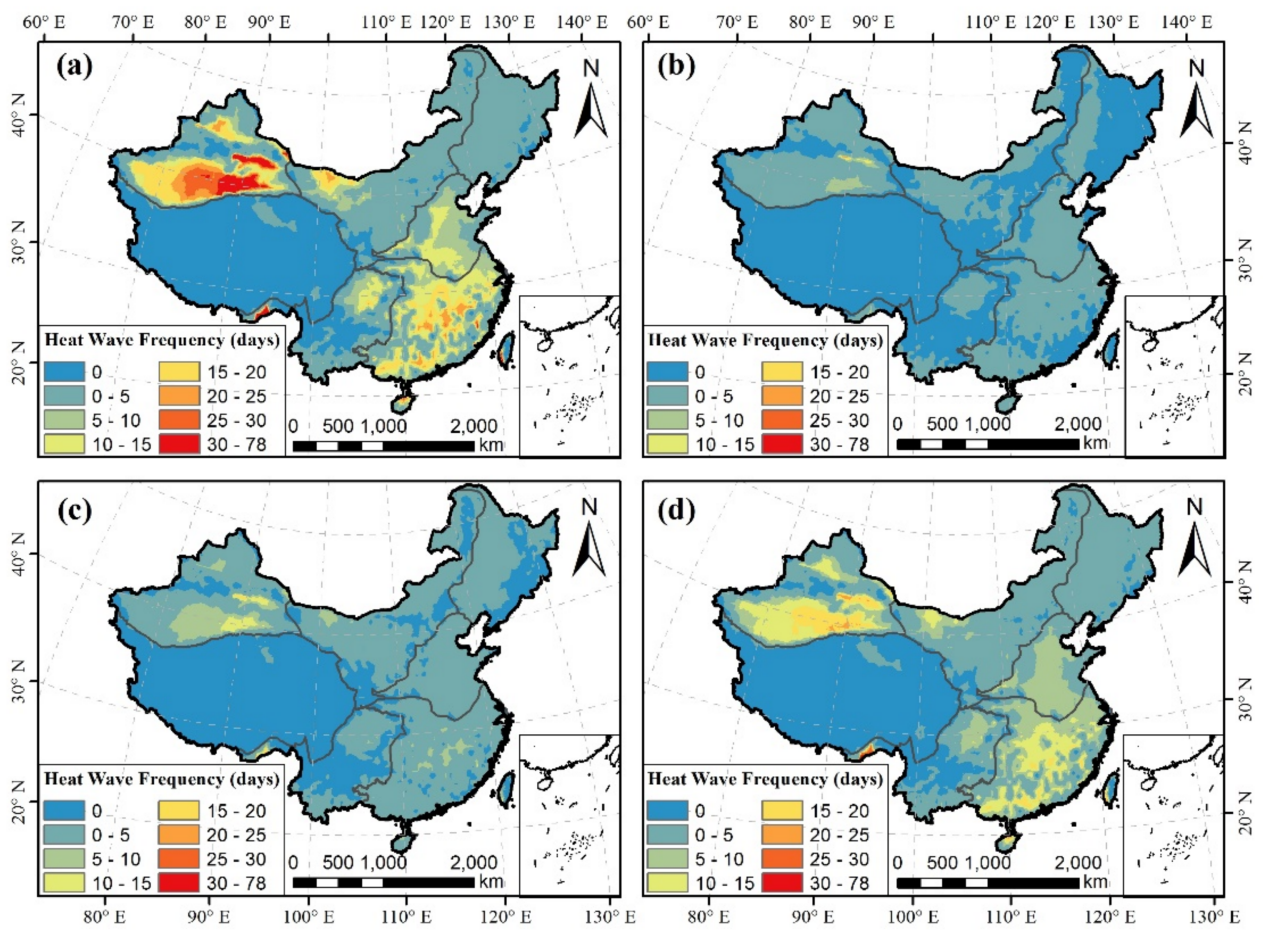

Figure 5. Spatial distribution of average annual (a) total heatwave frequency, (b) severe heatwave frequency, (c) moderate heatwave frequency, and (d) light heatwave frequency over China during 1979-2018. Total heatwave frequency is sum of severe, moderate, and light heatwave frequencies.

Figure 7 shows the spatial variation of THWF, LHWF, MHWF, and SHWF over China during 1979-2018. Figure 7a,e shows that the THWF of the majority of XJ and SC and northern SW experienced a relatively larger increasing trend than that of other subregions, at the significant level of 0.05. In contrast, there was no apparent change in NE and QTP. Similar to the regional variation characteristics of HWF at different levels (see Figure 6), there was also a gradually decreasing change rate for LHWF, MHWF, and SHWF following a spatial pattern over most of the subregions (Figure $7 \mathrm{~b}-\mathrm{d}, \mathrm{f}-\mathrm{h}$ ), excluding $\mathrm{XJ}$. Instead, the change rate in $\mathrm{XJ}$ in terms of SHWF was much larger than that of LWHF at the significant level of 0.05. A detailed description of the statistical procedure on the variation of THWF, LHWF, MHWF, and SHWF over China and subregions is provided in Table 3. As indicated, more than $40 \%$ of the area in China and subregions has an increasing trend at different HWF levels, in which more than $30 \%$ of the area was significant at the 0.05 level. With a gradual rise in temperature in the future and the increase of humidity in some regions (e.g., $\mathrm{XJ}$ ), light $H W$ is likely to appear in new regions, and original light $H W$ will turn into moderate HW or even severe $H W$. The government and the public should adopt effective measures to deal with the risks brought by the significantly increasing heatwave frequency.

\subsection{Change Trends of Key Parameters at Different Heatwave Levels}

According to Equations (7)-(9), these parameters were calculated for all years, as exhibited in Figure 8. The light $H W O$ was the earliest among the three levels over China, which started on July 3 on average, while the moderate and severe HWO started on July 12 and July 19, respectively. In the past few decades, the mean HWO of the light class was $8.6 \mathrm{~d}$ and $15.9 \mathrm{~d}$ earlier than that of moderate and severe classes. In terms of subregions, the HWO of the light class in XJ was approximately in June, while those of moderate and severe classes were approximately in July. In NE and NW, their HWO was stable at the 
three levels, approximately in June and July, respectively. Similarly, in NC, the light and moderate HWO occurred in June, and the severe HWO took place in July. However, in SC, the light and moderate HWO occurred in July, and the severe HWO was in August, while in SW, the light $H W O$ occurred in July, and the moderate and severe HWO occurred in August.
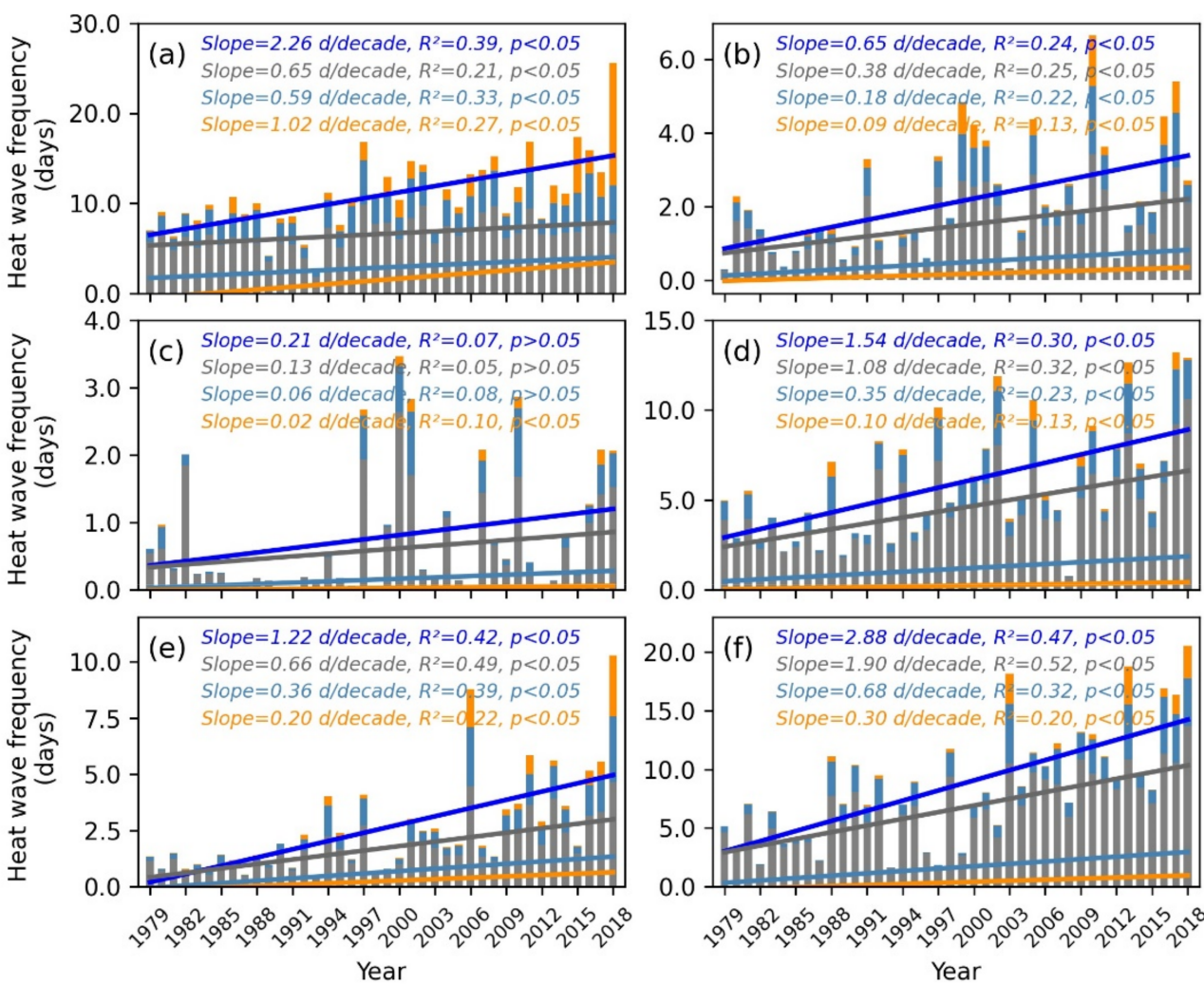

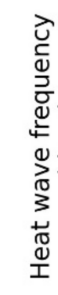

Legend

Legend
(LHWF)

Light heat wave frequency (LHWF)
Moderate heat wave frequency (MHWF)
Severe heat wave frequency (SHWF)
$\begin{aligned} & \text { Linear fitting of THWF } \\ & \text { Linear fitting of MHWF }\end{aligned}$

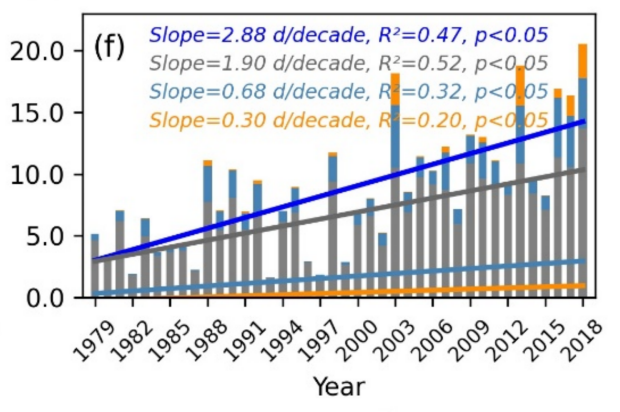

Figure 6. Temporal changes of light, moderate, and severe heatwave frequencies (to be regarded as LHWF, MHWF, and SHWF, respectively) over different subregions during 1979-2018. (a) XJ, (b) NW, (c) NE, (d) NC, (e) SW, and (f) SC. Since trend of HWF over QTP at region-scale was far less than $0.01 \mathrm{~d} /$ decade and was not significant, it was omitted here. THWF = total heatwave frequency, which means sum of LHWF, MHWF, and SHWF.

Table 3. Statistics of positive change rate (PCR) and significance (Sig.) percentage (\%) in different regions.

\begin{tabular}{ccccccccc}
\hline \multirow{2}{*}{ Region } & \multicolumn{2}{c}{ THWF } & \multicolumn{2}{c}{ LHWF } & \multicolumn{2}{c}{ MHWF } & \multicolumn{2}{c}{ SHWF } \\
\cline { 2 - 8 } & PCR * & Sig. * & PCR & Sig. & PCR & Sig. & PCR & Sig. \\
\hline China & 66.7 & 37.3 & 64.8 & 32.1 & 57.1 & 21.7 & 42.4 & 14.5 \\
XJ & 89.7 & 57.3 & 80.5 & 37.7 & 81.8 & 46.1 & 80.3 & 55.2 \\
QTP & 4.6 & 0.1 & 4.6 & 0.1 & 1.4 & 0 & 0.4 & 0 \\
NW & 91.8 & 44.7 & 91.4 & 35.6 & 74.5 & 19.7 & 44.6 & 8.3 \\
NE & 80.4 & 9.4 & 77.6 & 10.1 & 65.5 & 6.9 & 28.2 & 2.7 \\
NC & 98.0 & 63.1 & 97.9 & 60.3 & 91.9 & 24.5 & 72.4 & 7.3 \\
SW & 64.4 & 36.0 & 63.2 & 34.6 & 48.0 & 21.3 & 35.2 & 11.4 \\
SC & 96.4 & 83.2 & 96.4 & 80.5 & 89.6 & 46.5 & 73.4 & 17.8 \\
\hline
\end{tabular}

* The proportion of the area with the area of positive change rates (PCR) or significant area (Sig., $p<0.05)$ to the total area of the region. 

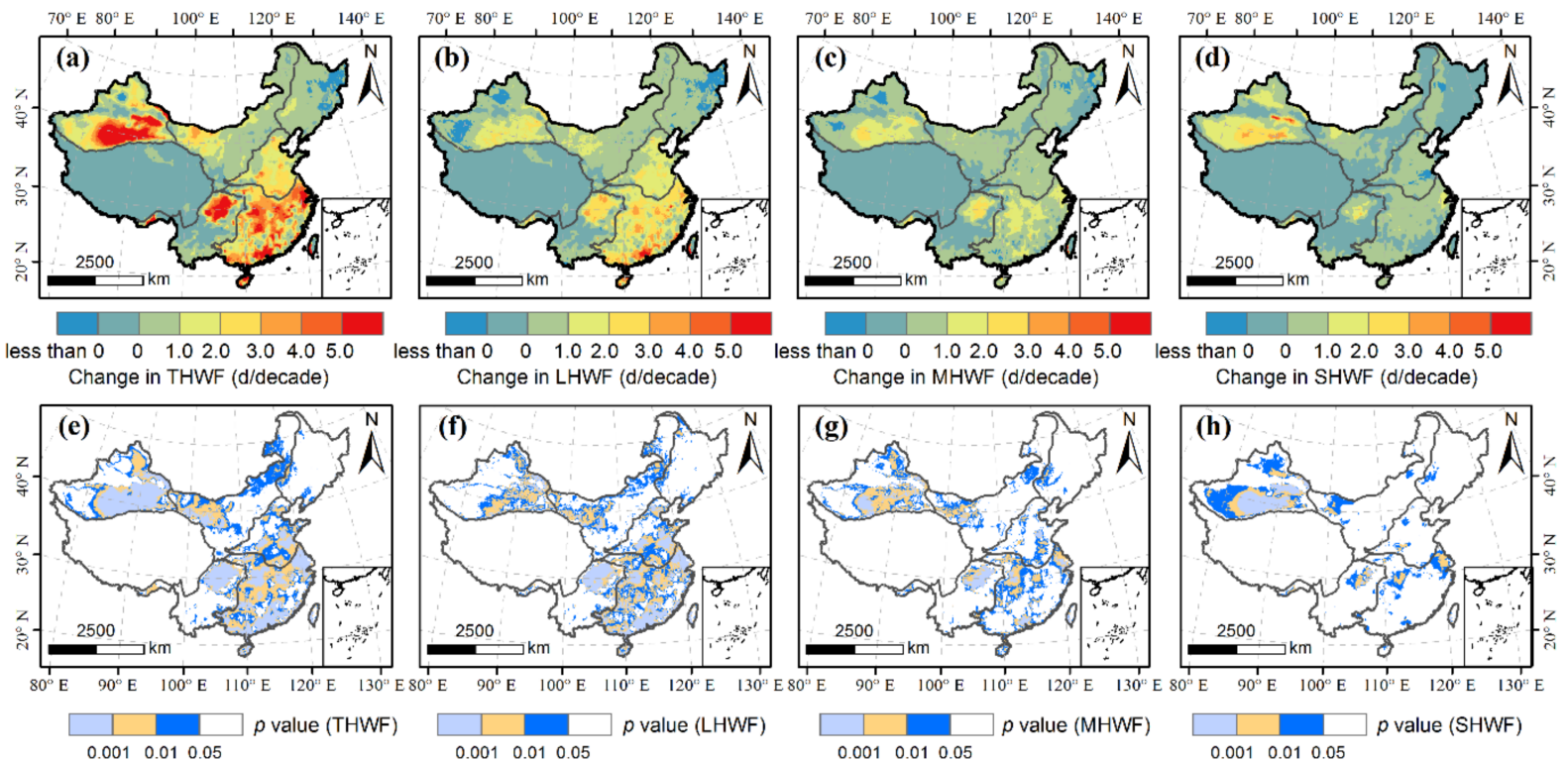

Figure 7. Changes in HWF over China during period 1979-2018. (a-d) Change trend in THWF, LHWF, MHWF, and SHWF, respectively; (e-h) corresponding $p$ values for HWF, in which $p<0.001, p<0.01$, and $p<0.05$ indicate whether corresponding change trend is significant at level of $0.001,0.01$, and 0.05 , respectively.
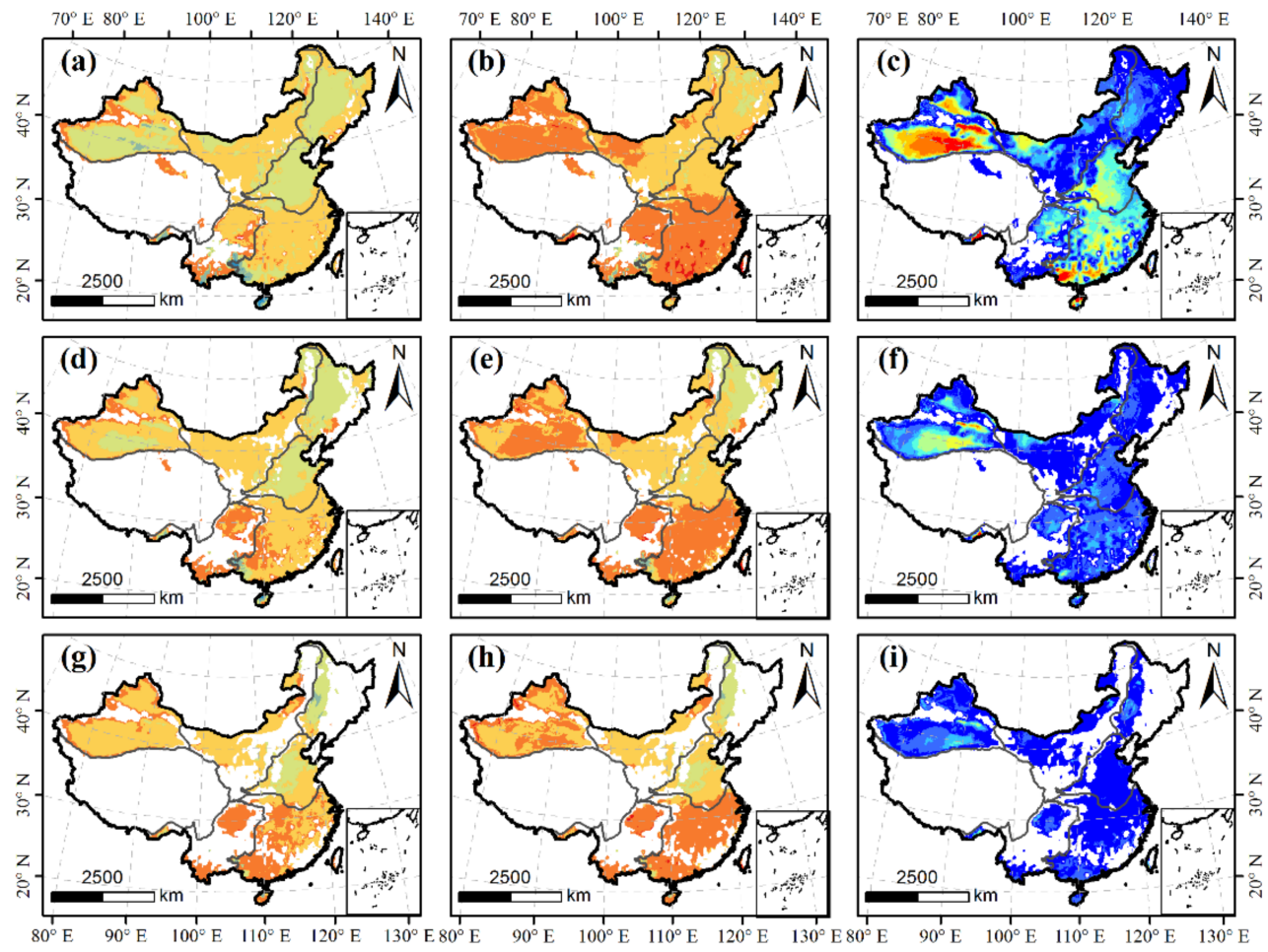

Start and end of heat wave season

Heat wave duration (days)

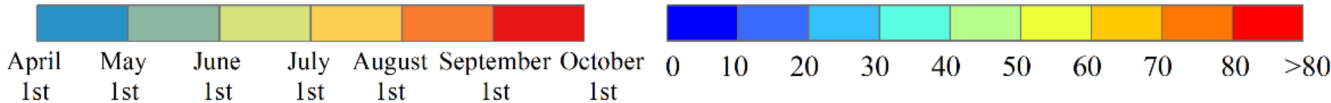

Figure 8. Average heatwave onset, termination, and duration at different levels for years from 1979 to 2018. First $(\mathbf{a}, \mathbf{d}, \mathbf{g})$, second $(\mathbf{b}, \mathbf{e}, \mathbf{h})$, and third $(\mathbf{c}, \mathbf{f}, \mathbf{i})$ columns are the onset, termination, and duration, respectively. First $(\mathbf{a}-\mathbf{c})$, second $(\mathbf{d}-\mathbf{f})$, and third $(\mathbf{g}-\mathbf{i})$ rows are light heatwave, moderate heatwave, and severe heatwave, respectively. 
Figure 8b,e,h shows the light HWT was the latest among the three levels over China, which ended on July 28 on average, and it was $5.4 \mathrm{~d}$ and $2.5 \mathrm{~d}$ later than moderate and severe HWT. Among seven subregions, the HWT in XJ, SC, and SW was the latest in August, followed by NW and NC in July, and finally, NE in June. Figure 8c,f,i illustrates the average $H W D$ over China from 1979 to 2018. It is indicated that the high-value areas in HWD are located in XJ, SC, and NC. The details surrounding the mean HWO, HWT, and HWD over seven subregions are provided in Table 4.

Table 4. Onset, termination, and duration of heatwaves at different levels over seven subregions.

\begin{tabular}{cccccccccc}
\hline \multirow{2}{*}{ Region } & \multicolumn{3}{c}{ Light } & \multicolumn{3}{c}{ Moderate } & \multicolumn{2}{c}{ Severe } \\
\cline { 2 - 9 } & Start & End & Duration & Start & End & Duration & Start & End & Duration \\
\hline XJ & $6 / 30$ & $8 / 9$ & 40 & $7 / 13$ & $8 / 2$ & 20 & $7 / 20$ & $7 / 31$ & 11 \\
QTP & $8 / 4$ & $8 / 6$ & 2 & $8 / 5$ & $8 / 8$ & 3 & $8 / 13$ & $8 / 19$ & 6 \\
NW & $7 / 6$ & $7 / 19$ & 13 & $7 / 11$ & $7 / 16$ & 5 & $7 / 16$ & $7 / 19$ & 3 \\
NE & $6 / 28$ & $7 / 6$ & 9 & $6 / 24$ & $6 / 28$ & 5 & $6 / 18$ & $6 / 23$ & 5 \\
NC & $6 / 19$ & $7 / 19$ & 30 & $6 / 28$ & $7 / 8$ & 10 & $7 / 4$ & $7 / 6$ & 2 \\
SW & $7 / 16$ & $8 / 3$ & 18 & $8 / 1$ & $8 / 12$ & 10 & $8 / 9$ & $8 / 17$ & 7 \\
SC & $7 / 6$ & $8 / 10$ & 36 & $7 / 20$ & $7 / 31$ & 12 & $7 / 29$ & $8 / 5$ & 6 \\
\hline \multicolumn{8}{c}{ The format of "6/30" means month/day. }
\end{tabular}

Overall, the HWO and the HWT in China showed advancement and postponement at different levels, respectively (Figure 9). However, the variation characteristics had large differences in subregions. When combined with Table 5 and Figure 9, it was found that for light HW, the HWO advanced in most subregions, except for QTP. In QTP, 27.4\% of heatwave area had a progressive trend in $H W O$, and $69.4 \%$ of the area had a delayed $H W T$, which finally resulted in $23.8 \%$ of the area showing an increasing trend. However, in the other six subregions, the areas where the HWO and HWT advanced and delayed accounted for more than $60 \%$, resulting in a significant increase in HWD over a large area.

Table 5. Area percentage (\%) of advanced heatwave onset, delayed heatwave termination, and increasing heatwave duration in seven subregions of China.

\begin{tabular}{ccccccccc}
\hline \multirow{2}{*}{ Region } & \multicolumn{3}{c}{ Light } & \multicolumn{3}{c}{ Moderate } & \multicolumn{2}{c}{ Severe } \\
\cline { 2 - 8 } & Onset & \multicolumn{2}{c}{ Termination Duration } & Onset & Termination Duration & Onset & Termination Duration \\
\hline XJ & 87.7 & 92.6 & 97.0 & 77.4 & 78.9 & 88.7 & 56.7 & 95.5 \\
QTP & 27.4 & 69.4 & 23.8 & 10.0 & 90.0 & 50.0 & 31.6 & 67.8 \\
NW & 68.9 & 62.9 & 77.6 & 63.8 & 56.1 & 70.4 & 55.6 & 63.3 \\
NE & 69.1 & 49.3 & 62.0 & 77.0 & 34.8 & 53.9 & 78.1 & 46.5 \\
NC & 65.3 & 87.4 & 89.3 & 31.9 & 82.8 & 74.3 & 31.6 & 67.8 \\
SW & 60.4 & 89.5 & 88.4 & 68.2 & 75.4 & 84.8 & 68.2 & 45.1 \\
SC & 85.8 & 95.4 & 95.9 & 50.3 & 82.5 & 81.6 & 38.8 & 67.9 \\
\hline
\end{tabular}

Similar to the light class $H W$, the onset and termination of the moderate $H W$ were also mainly characterized by advancement and postponement in most subregions, except QTP, NC, and NE. The HWO of QTP was not obviously advanced. Instead, the increase in $H W D$ of the region was dominated by a delay in HWO. At present, although the range of moderate heatwaves in this region was very small (See Table 3), it is likely to be further strengthened and expanded in the future under the influence of global warming. In NC, the main reason for the increase in $H W D$ was the delay in HWT rather than the advancement of $H W O$. On the contrary, the dominant factor leading to an increase in HWD in NE was the advancement of $H W O$ rather than the postponement of HWT. 

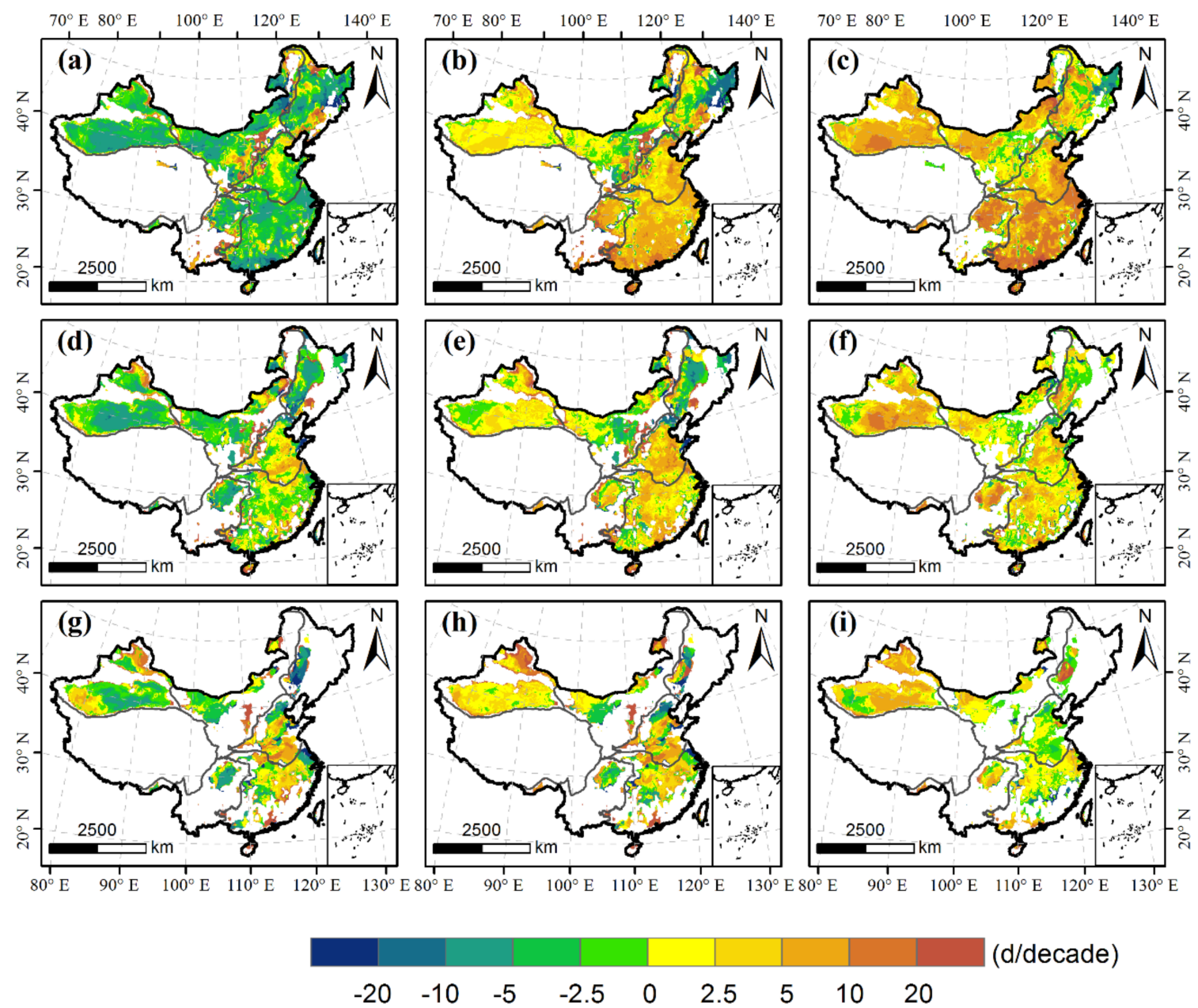

Figure 9. Trend of heatwave onset, termination, and duration at different levels for years from 1979 to 2018. First (a,d,g), second $(\mathbf{b}, \mathbf{e}, \mathbf{h})$, and third $(\mathbf{c}, \mathbf{f}, \mathbf{i})$ columns were onset, termination, and duration, respectively. First $(\mathbf{a}-\mathbf{c})$, second $(\mathbf{d}-\mathbf{f})$, and third $(\mathbf{g}-\mathbf{i})$ rows are light heatwave, moderate heatwave, and severe heatwave, respectively.

As for the severe $H W$, only $\mathrm{XJ}$ and NW showed an advancement and postponement of $H W O$ and $H W T$, respectively, among seven subregions in China. In QTP, NC, and SC, the main reason for the increase in $H W D$ was the postponement of $H W T$, while the opposite holds true in NE and SW, where the advancement of $H W O$ was the dominant factor in increasing the HWD.

\section{Discussion}

This study evaluated the spatiotemporal changes of heatwaves in China. To fulfill this goal, we used the gridded maximum temperature product. This dataset was made available by the National Meteorological Information Center (NMIC) and the National Tibetan Plateau/Third Pole Environment Data Center (TPDC), and it was already quality checked by the provider. The gridded dataset is the product of interpolating more than 2400 stations distributed across the country, and therefore provides a very accurate and detailed measure of temperature and humidity changes in China. The impact of heatwaves on human body was also evaluated by including specific humidity as an auxiliary parameter.

Our analysis demonstrates that as the result of climate change, the number of hightemperature days was on the rise in China over the past few decades. Similarly, Chen et al. [42], by applying a variable-grid atmospheric general circulation model, found a significant increase in the mean, daily maximum, and minimum temperatures over China (with an emphasis on the Southeast China) with a concurrent decrease in the number of frost days. Zhou and Ren [43] also reported that the numbers of frost and ice days in China signif- 
icantly reduced during 1961-2008, while summer days and tropical nights significantly increased. A very interesting case among the seven subregions studied was the QinghaiTibetan Plateau (QTP), which had the slightest high-temperature days (HTDs) rising rate $(0.01 \mathrm{~d} /$ decade). However, it may have relatively more severe impacts on the heatwaves by directly or potentially impacting the climate and environment of the surrounding regions, or even the global climate. Wu et al. [44] also found positive feedback between changes in QTP snow cover and heatwaves in China; therefore, changes in high-temperature days not only affect the Tibetan plateau, but can also strengthen heatwaves in China and over the globe. Southern China (SC), which is home to more than $39.9 \%$ of the total population of China, had the fastest increasing HTDs trend at the rate of $4.86 \mathrm{~d} /$ decade, implying the highest level of population exposure to extremely high temperatures. We also evaluated the spatial changes in HTDs and found that overall, the interannual variability of HTDs in the north and south has great differences, which are probably caused by the change of atmospheric circulation [45]. For northern China, the primary circulation is the overlying geopotential height anomaly at middle-to-upper levels, while for southern China, besides that, the major circulations also include temperature advection by the meridional wind at lower levels. Global warming, on the other hand, also affects ocean currents, and hence, heatwaves in most areas of China. Collins, et al. [46] concluded that the mean climate of the Pacific will be markedly altered by climate change, resulting in the weakening of trade winds, higher ocean surface temperatures, a steeper temperature gradient, and eventually, stronger tropical Pacific Ocean fluctuations, and hence, El Niño-dependent events. Based on the results of Luo et al. [47], the climate of most areas in China and especially the Southern China are sensitive to the El Niño activities, and hence, climate change, by impacting Pacific Ocean fluctuations, which will result in higher temperatures and therefore stronger, more frequent, and more prolonged heatwaves in China.

Besides high temperature, for a heatwave to occur, it also requires a certain level of relative humidity. One of the consequences of rising temperatures due to climate change is the concurrent rise in air humidity and the likelihood of humid-heatwave occurrence. Based on our findings, due to the climate-change-driven gradual rise of temperature in the future and the increase of humidity in some regions (e.g., $\mathrm{XJ}$ ), light $\mathrm{HW}$ is likely to appear in new regions in China, while original light HW will turn into moderate HW or even severe HW. According to Russo, et al. [48] climate change and the resulting rise in humidity, have amplified and will continue to affect the magnitude and apparent temperature peak of heat waves over the globe. Climate model projections suggest that the percentage of area where heat wave magnitude and peak are amplified by humidity increases with increasing warming levels. Furthermore, studies $[48,49]$ showed that humid HWs reaching to as high as $55{ }^{\circ} \mathrm{C}$ in China will be nothing of a surprise in the future. Given a $4{ }^{\circ} \mathrm{C}$ increase in the mean temperature, extreme humid-heatwaves are likely to occur every other year. Dry HWs are more common in northern China, while humid HWs are more widespread in southern and southeastern sections of this country. Climate change and the rising temperatures will result in more severe humid HWs in the southern parts of China [50]. Similar results were reported for dry HWs by Matthews [51] and Kang, et al. [52] for the Northern China Plain. The government and the public sectors should adopt effective measures to deal with the risks brought by the increasing heatwave frequency. With the intensification of global warming, severe heatwaves are likely to occur in the future, and the area under the influence of heatwaves will expand to a certain extent. Sun et al. (2017) argued that $50 \%$ of land area in China is projected to be affected by intense heat waves. They further claimed that the likelihood of concurrent droughts and heatwaves is another source of concern for China during the 21st century. According to Russo, et al. [49] and Guo, et al. [25], under the impact of climate change, severe heat waves will become more frequent, and they will expand to larger areas in China.

We also investigated heatwave frequency to better illustrate the difference between heatwaves and HTDs. Accordingly, all the total heatwave frequency (THWF), light heatwave frequency (LHWF), moderate heatwave frequency (MHWF), and severe heatwave 
frequency (SHWF) had an increasing trend over the seven subregions. The THWF changes were relatively larger over SC and $\mathrm{XJ}$ than that of other subregions, with a change rate of $2.88 \mathrm{~d}$ / decade and $2.26 \mathrm{~d} /$ decade, respectively. Yuan et al. [53] reported the strongest recorded heatwave before 2015 in SC (Figure 6f). We believe that even under the businessas-usual scenario, global warming will continue to exacerbate heat wave in China in all aspects of frequency, intensity, and duration. In line with our claim and by evaluating the results of 12 global climate change models, Guo, et al. [25] found out that frequency and intensity of heat waves in China are projected to increase noticeably in respond to rising global mean temperature.

Another important heatwave variable besides extent, frequency, and variability is the heatwave onset, termination, and duration. Accordingly, light heat waves have the earliest onset in all parts of China, happening in a range of June to July. This category also has the latest termination. Xinjiang (XJ) had the longest duration for all three categories of light, moderate, and severe heatwaves. These findings are basically the same as Jia and $\mathrm{Hu}$ [54], although different heatwave classification methods were employed. Based on our results, the heatwave onset (HWO) and the heatwave termination (HWT) in China showed advancement and postponement at different levels, yet with great variations in different subregions. As for heatwave duration (HWD), we found that its variations depend mostly on the advancement of the onset or the postponement of the termination or a combination thereof. We failed to find similar studies in terms of the impact of climate change on HW onset and termination in China, but according to the climate change projections using 4 global models by Yang, et al. [55] for the $1.5^{\circ} \mathrm{C}$ and $2{ }^{\circ} \mathrm{C}$ of warming targets and similar to our finding, China will suffer heatwaves with longer durations and greater intensity in the future. Similar results were obtained by Dosio, et al. [56] and Perkins-Kirkpatrick, et al. [1] elsewhere.

The elongation of heatwaves, along with their severity and frequency, affect China's economy in the first place, which directly or indirectly affect public and household welfare. For example, Xia et al. [57] reported that "extreme heat can not only induce health outcomes in terms of excess mortality and morbidity (hospital admissions) but can also cause productivity losses for self-paced indoor workers and capacity losses for outdoor workers due to occupational safety requirements". Heatwaves can also impact human health in a significant manner. According to $\mathrm{Hu}$ et al. [58], heatwaves result in higher mortality rates and even suicides in in Shenzhen, China. In a nutshell, heatwaves are going to intensify in China in the future in response to climate change, and this perilous phenomenon requires preparation and mitigation programs to be in place to either avoid or mitigate the impact of extreme weather events due to climate change [48,59].

Overall, these findings presented in this study can provide a reference for the early warning and forecasting of HW over China. However, the quantitative risk assessment and evolution mechanism of HW events were not investigated in this study, which needs further specialized study.

\section{Summary and Conclusions}

In this study, the temporal and spatial variation of high-temperature days and the heatwave frequency at different levels were analyzed in seven subregions of China. Finally, the trend analysis was carried out during the study period to identify the heatwave onset, termination, and duration at different levels. The main findings in the present study can be summarized as follows:

There were noticeable regional differences in terms of the mean number of hightemperature days in seven subregions of China, with larger values in Xinjiang (XJ), Southern China (SC), and Northern China (NC). Overall, from the perspective of interannual variation, the high-temperature day (HTD) showed a significant increasing trend in all subregions except Northeast (NE). Similar to HTDs, XJ, SC, and NC had higher heatwave frequencies. Furthermore, among the three heatwave levels, the light heatwave level had the highest frequency, followed by moderate and severe heatwave frequencies in the seven 
subregions of China. The change rates of heatwave frequency gradually tapered off from the light to the severe, but not for $\mathrm{XJ}$, where the rate of the severe was larger than the light. It indicated that the change of heatwave frequency over other subregions was relatively milder than that of XJ. From the perspective of spatial variation of heatwave frequency, the majority of $\mathrm{XJ}$ and SC and northern Southwest (SW) experienced a relatively larger increasing trend than other subregions, at the significant level of 0.05 . In contrast, there were no apparent changes in the NE and Qinghai-Tibetan Plateau (QTP).

The heatwave onset (HWO) at the light level was the earliest among the three levels over China, which started on 3 July on average, and it was $8.6 \mathrm{~d}$ and $15.9 \mathrm{~d}$ earlier than the moderate and the severe, respectively. Similarly, the heatwave termination (HWT) at the light level was the latest among the three levels over China, which ended on July 28 on average, and it was $5.4 \mathrm{~d}$ and $2.5 \mathrm{~d}$ later than the moderate and the severe. Therefore, the heatwave duration $(H W D)$ at the light level was the longest among the three levels. Furthermore, among the seven subregions in China, heatwave at all levels started relatively earlier in northwest (NW), NE, and NC, and ended later in XJ, Southern China (SC), and Southwest (SW). Although heatwave onset in NE started earlier, the heatwave termination in this region ended very quickly, resulting in a short heatwave duration, while $\mathrm{XJ}, \mathrm{SC}$, and NC had a long heatwave duration due to early heatwave onset and late heatwave termination. In particular, QTP had the shortest mean heatwave duration at all three levels for the joint effect of the heatwave onset and heatwave termination.

There was an overall increasing trend in heatwave duration over China, which resulted from the combined effect of the heatwave onset and heatwave termination. However, the variations of the heatwave onset and heatwave termination had large differences among seven subregions and three levels. Among them, XJ and NW were primarily characterized by an advanced heatwave onset and delayed heatwave termination at the three levels, while a delay of heatwave termination mainly characterized QTP. Contrary to QTP, the heatwave onset in NE was characterized by an advance at the three levels. In other subregions (NC, SW, and SC), the changes in heatwave onset and heatwave termination were noticeably different among the light, moderate, and severe levels.

Author Contributions: J.L. and Y.R. conceived the idea; J.L., Y.R. and H.T. designed the experiment; J.L. collected and analyzed the data; J.L. took the lead in writing the manuscript; M.J.S. participated in writing and polished the manuscript. All authors provided critical feedback and helped shape the research, analyses, and manuscript. All authors have read and agreed to the published version of the manuscript.

Funding: This work was funded by the National Key Research and Development Program of China, (Grant No. 2018FY100501) and CAS “Light of West China” Program (2019-XBQNXZ-B-004\&2019XBYJRC-001).

Data Availability Statement: The data presented in this study are available on request from the corresponding author.

Acknowledgments: The authors would like to thank the National Meteorological Information Center (NMIC), National Tibetan Plat-eau/Third Pole Environment Data Center (TPDC), and Resource and Environment Science and Data Center (RESDC) for providing support with the observational and assimilative data. Also, we thank the anonymous reviewers for their useful feedback that improved this paper.

Conflicts of Interest: The authors declare no conflict of interest. 


\section{Appendix A}

Table A1. All abbreviations and corresponding full names presented in this study.

\begin{tabular}{|c|c|c|}
\hline Classification & Abbreviation & Full Name \\
\hline \multirow{7}{*}{ Place name } & $\mathrm{XJ}$ & Xinjiang \\
\hline & QTP & Qinghai-Tibetan Plateau \\
\hline & $\hat{N W}$ & Northwest \\
\hline & NE & Northeast \\
\hline & NC & Northern China \\
\hline & SW & Southwest \\
\hline & SC & Southern China \\
\hline \multirow{2}{*}{ Climate variables } & MAXT & maximum temperature \\
\hline & $\mathrm{SH}$ & Specific Humidity \\
\hline Temperature parameter & HTD & High Temperature Day \\
\hline \multirow{10}{*}{ Heatwave parameters } & $H W$ & Heatwave \\
\hline & HWI & Heatwave index \\
\hline & HWO & Onset of heatwave \\
\hline & $H W T$ & Termination of heatwave \\
\hline & $H W D$ & Heatwave duration \\
\hline & HWF & Heatwave frequency \\
\hline & THWF & Total heatwave frequency \\
\hline & LHWF & Light heatwave frequency \\
\hline & MHWF & Moderate heatwave frequency \\
\hline & SHWF & Severe heatwave frequency \\
\hline \multirow{8}{*}{ Program/Mission } & TRMM & $\begin{array}{c}\text { Tropical Rainfall Monitoring } \\
\text { Mission }\end{array}$ \\
\hline & GLDAS & Global Land Data \\
\hline & GLDAS & Assimilation System \\
\hline & & Global Energy and Water \\
\hline & GEWEX-SRB & Exchanges-Surface Radiation \\
\hline & & Budget \\
\hline & & Modern-Era Retrospective \\
\hline & MERRA & $\begin{array}{c}\text { analysis for Research and } \\
\text { Applications }\end{array}$ \\
\hline Method & TPS & Thin Plate Spline \\
\hline \multirow{7}{*}{ Organization } & CMA & $\begin{array}{l}\text { China Meteorological } \\
\text { Administration }\end{array}$ \\
\hline & RESDC & $\begin{array}{l}\text { Resource and Environment } \\
\text { Science and Data Center }\end{array}$ \\
\hline & & National Tibetan \\
\hline & TPDC & Plateau/Third Pole \\
\hline & & Environment Data Center \\
\hline & NMIC & $\begin{array}{l}\text { National Meteorological } \\
\text { Information Center }\end{array}$ \\
\hline & WMO & $\begin{array}{l}\text { World Meteorological } \\
\text { Organization }\end{array}$ \\
\hline
\end{tabular}

\section{References}

1. Perkins-Kirkpatrick, S.E.; Lewis, S.C. Increasing trends in regional heatwaves. Nat. Commun. 2020, 11, 3357. [CrossRef]

2. Qin, D.; Ding, Y.; Mu, M. Climate and Environmental Change in China: 1951-2012; Springer: Berlin/Heidelberg, Germany, 2016.

3. Anderson, G.B.; Bell, M.L.; Peng, R.D. Methods to calculate the heat index as an exposure metric in environmental health research. Environ. Health Perspect. 2013, 121, 1111-1119. [CrossRef]

4. Steadman, R.G. The assessment of sultriness. Part I: A temperature-humidity index based on human physiology and clothing science. J. Appl. Meteorol. 1979, 18, 861-873. [CrossRef]

5. Erdenebat, E.; Sato, T. Recent increase in heat wave frequency around Mongolia: Role of atmospheric forcing and possible influence of soil moisture deficit. Atmos. Sci. Lett. 2016, 17, 135-140. [CrossRef] 
6. Habeeb, D.; Vargo, J.; Stone, B. Rising heat wave trends in large US cities. Nat. Hazards 2015, 76, 1651-1665. [CrossRef]

7. Kuglitsch, F.G. Heat wave changes in the eastern Mediterranean since 1960. Geophys. Res. Lett. 2010, 37, L04802. [CrossRef]

8. Perkins, S.E.; Alexander, L.V.; Nairn, J.R. Increasing frequency, intensity and duration of observed global heatwaves and warm spells. Geophys. Res. Lett. 2012, 39, L20714. [CrossRef]

9. Campbell, S.; Remenyi, T.; White, C.; Johnston, F. Heatwave and health impact research: A global review. Health Place 2018, 53, 210-218. [CrossRef]

10. Chen, K.; Huang, L.; Zhou, L.; Ma, Z.; Bi, J.; Li, T. Spatial analysis of the effect of the 2010 heat wave on stroke mortality in Nanjing, China. Sci. Rep. 2015, 5, 10816. [CrossRef]

11. Mitchell, D.; Heaviside, C.; Vardoulakis, S.; Huntingford, C.; Masato, G.; Guillod, P.B.; Frumhoff, P.; Bowery, A.; Wallom, D.; Allen, M. Attributing human mortality during extreme heat waves to anthropogenic climate change. Environ. Res. Lett. 2016, 11, 074006. [CrossRef]

12. Åström, O.D.; Forsberg, B.; Ebi, K.L.; Rocklöv, J. Attributing mortality from extreme temperatures to climate change in Stockholm, Sweden. Nat. Clim. Chang. 2013, 3, 1050-1054. [CrossRef]

13. Vardoulakis, S. Comparative assessment of the effects of climate change on heat-and cold-related mortality in the United Kingdom and Australia. Environ. Health Perspect. 2014, 122, A320. [CrossRef]

14. Black, M.T.; Karoly, D.J.; King, A.D. The contribution of anthropogenic forcing to the Adelaide and Melbourne, Australia, heat waves of January 2014. Bull. Am. Meteorol. Soc. 2015, 96, S145-S148. [CrossRef]

15. Dong, B.; Sutton, R.; Shaffrey, L.; Wilcox, L. The 2015 European heat wave. Bull. Am. Meteorol. Soc. 2016, 97, S57-S62. [CrossRef]

16. Wang, J.; Yan, Z.; Quan, X.-W.; Feng, J. Urban warming in the 2013 summer heat wave in eastern China. Clim. Dyn. 2017, 48, 3015-3033. [CrossRef]

17. Anderson, B.; Bell, M. Heat waves in the United States: Mortality risk during heat waves and effect modification by heat wave characteristics in 43 USA communities. Environ. Health Perspect. 2010, 119, 210-218. [CrossRef]

18. Ma, F.; Yuan, X.; Jiao, Y.; Ji, P. Unprecedented Europe heat in June-July 2019: Risk in the historical and future context. Geophys. Res. Lett. 2020, 47, e2020GL087809. [CrossRef]

19. Huang, W.; Kan, H.; Kovats, S. The impact of the 2003 heat wave on mortality in Shanghai, China. Sci. Total Environ. 2010, 408, 2418-2420. [CrossRef] [PubMed]

20. Tan, J.; Zheng, Y.; Song, G.; Kalkstein, L.S.; Kalkstein, A.J.; Tang, X. Heat wave impacts on mortality in Shanghai, 1998 and 2003. Int. J. Biometeorol. 2007, 51, 193-200. [CrossRef] [PubMed]

21. Sun, X.; Sun, Q.; Zhou, X.; Li, X.; Yang, M.; Yu, A.; Geng, F. Heat wave impact on mortality in Pudong New Area, China in 2013. Sci. Total Environ. 2014, 493, 789-794. [CrossRef] [PubMed]

22. Peng, J. An investigation of the formation of the heat wave in Southern China in summer 2013 and the relevant abnormal subtropical high activities. Atmos. Ocean. Sci. Lett. 2014, 7, 286-290. [CrossRef]

23. Ding, T.; Ke, Z. Characteristics and changes of regional wet and dry heat wave events in China during 1960-2013. Theor. Appl. Climatol. 2015, 122, 651-665. [CrossRef]

24. Ye, D.-X.; Yin, J.; Chen, Z.-H.; Zheng, Y.-F.; Wu, R.-J. Spatial and temporal variations of heat waves in China from 1961 to 2010. Adv. Clim. Chang. Res. 2014, 5, 66-73. [CrossRef]

25. Guo, X.; Huang, J.; Luo, Y.; Zhao, Z.; Xu, Y. Projection of heat waves over China for eight different global warming targets using 12 CMIP5 models. Theor. Appl. Climatol. 2017, 128, 507-522. [CrossRef]

26. Basara, J.; Basara, H.; Illston, B.; Crawford, K. The impact of the urban heat island during an intense heat wave in Oklahoma city. Adv. Meteorol. 2010, 2010, 230365. [CrossRef]

27. Cristo, R.D.; Mazzarella, A.; Viola, R. An analysis of heat index over Naples (Southern Italy) in the context of European heat wave of 2003. Nat. Hazards 2007, 40, 373-379. [CrossRef]

28. Gaffen, D.J.; Ross, R.J. Climatology and trends of U.S. Surface humidity and temperature. J. Clim. 1999, 12, 811-828. [CrossRef]

29. Morjani, Z.E.A.E.; Ebener, S.; Boos, J.; Ghaffar, E.A.; Musani, A. Modelling the spatial distribution of five natural hazards in the context of the WHO/EMRO Atlas of Disaster Risk as a step towards the reduction of the health impact related to disasters. Int. J. Health Geogr. 2007, 6, 8. [CrossRef]

30. Patricola, C.M.; Cook, K.H. Northern African climate at the end of the twenty-first century: An integrated application of regional and global climate models. Clim. Dyn. 2010, 35, 193-212. [CrossRef]

31. Schoen, C. A new empirical model of the temperature-humidity index. J. Appl. Meteorol. 2005, 44, 1413-1420. [CrossRef]

32. Huang, Z.; Chen, H.; Tian, H. Research on the heat wave index. Meteorol. Mon. 2011, 37, 345-351.

33. Guo, H.; Bao, A.; Liu, T.; Chen, S.; Ndayisaba, F. Evaluation of PERSIANN-CDR for meteorological drought monitoring over China. Remote Sens. 2016, 8, 379. [CrossRef]

34. Tang, Z.; Wang, Z.; Zheng, C.; Fang, J. Biodiversity in China's mountains. Front. Ecol. Environ. 2006, 4, 347-352. [CrossRef]

35. Qian, W.; Lin, X. Regional trends in recent precipitation indices in China. Meteorol. Atmos. Phys. 2005, 90, 193-207. [CrossRef]

36. He, J.; Yang, K.; Tang, W.; Lu, H.; Qin, J.; Chen, Y.; Li, X. The first high-resolution meteorological forcing dataset for land process studies over China. Sci. Data 2020, 7, 25. [CrossRef]

37. Yang, K.; He, J. China Meteorological Forcing Dataset (1979-2018); National Tibetan Plateau Data Center: Beijing, China, 2019. [CrossRef] 
38. Yang, K.; He, J.; Tang, W.; Qin, J.; Cheng, C.C.K. On downward shortwave and longwave radiations over high altitude regions: Observation and modeling in the Tibetan Plateau. Agric. For. Meteorol. 2010, 150, 38-46. [CrossRef]

39. Murray, F.W. On the computation of saturation vapor pressure. J. Appl. Meteorol. Climatol. 1967, 6, 203-204. [CrossRef]

40. Shaman, J.; Kohn, M. Absolute humidity modulates influenza survival, transmission, and seasonality. Proc. Natl. Acad. Sci. USA 2009, 106, 3243-3248. [CrossRef]

41. Thom, E.C. The discomfort index. Weatherwise 1959, 12, 57-61. [CrossRef]

42. Chen, W.; Jiang, Z.; Li, L.; Yiou, P. Simulation of regional climate change under the IPCC A2 scenario in southeast China. Clim. Dyn. 2011, 36, 491-507. [CrossRef]

43. Zhou, Y.; Ren, G. Change in extreme temperature event frequency over mainland China, 1961-2008. Clim. Res. 2011, 50, 125-139. [CrossRef]

44. Wu, Z.; Jiang, Z.; Li, J.; Zhong, S.; Wang, L. Possible association of the western Tibetan Plateau snow cover with the decadal to interdecadal variations of northern China heatwave frequency. Clim. Dyn. 2012, 39, 2393-2402. [CrossRef]

45. Sun, J.; Wang, H.; Wei, A.Y. Decadal variability of the extreme hot event in China and its association with atmospheric circulations. Clim. Environ. Res. 2011, 16, 199-208.

46. Collins, M.; An, S.-I.; Cai, W.; Ganachaud, A.; Guilyardi, E.; Jin, F.-F.; Jochum, M.; Lengaigne, M.; Power, S.; Timmermann, A.; et al. The impact of global warming on the tropical Pacific Ocean and El Niño. Nat. Geosci. 2010, 3, 391-397. [CrossRef]

47. Luo, M.; Lau, N.-C. Amplifying effect of ENSO on heat waves in China. Clim. Dyn. 2019, 52, 3277-3289. [CrossRef]

48. Russo, S.; Sillmann, J.; Sterl, A. Humid heat waves at different warming levels. Sci. Rep. 2017, 7, 7477. [CrossRef]

49. Russo, S.; Dosio, A.; Graversen, R.G.; Sillmann, J.; Carrao, H.; Dunbar, M.B.; Singleton, A.; Montagna, P.; Barbola, P.; Vogt, J.V. Magnitude of extreme heat waves in present climate and their projection in a warming world. J. Geophys. Res. Atmos. 2014, 119, 12,500-12,512. [CrossRef]

50. Xu, F.; Chan, T.O.; Luo, M. Different changes in dry and humid heat waves over China. Int. J. Climatol. 2021, 41, 1369-1382. [CrossRef]

51. Matthews, T. Humid heat and climate change. Prog. Phys. Geogr. Earth Environ. 2018, 42, 391-405. [CrossRef]

52. Kang, S.; Eltahir, E.A.B. North China Plain threatened by deadly heatwaves due to climate change and irrigation. Nat. Commun. 2018, 9, 2894. [CrossRef]

53. Yuan, W.; Cai, W.; Chen, Y.; Liu, S.; Dong, W.; Zhang, H.; Yu, G.; Chen, Z.; He, H.; Guo, W.; et al. Severe summer heatwave and drought strongly reduced carbon uptake in Southern China. Sci. Rep. 2016, 6, 18813. [CrossRef] [PubMed]

54. Jia, J.; Hu, Z. Spatial and temporal features and trend of different level heat waves over China. Adv. Earth Sci. 2017, 32, 546-559.

55. Yang, Y.; Jin, C.; Ali, S. Projection of heat wave in China under global warming targets of $1.5^{\circ} \mathrm{C}$ and $2{ }^{\circ} \mathrm{C}$ by the ISIMIP models. Atmos. Res. 2020, 244, 105057. [CrossRef]

56. Dosio, A.; Mentaschi, L.; Fischer, E.M.; Wyser, K. Extreme heat waves under $1.5^{\circ} \mathrm{C}$ and $2{ }^{\circ} \mathrm{C}$ global warming. Environ. Res. Lett. 2018, 13, 054006. [CrossRef]

57. Xia, Y.; Li, Y.; Guan, D.; Tinoco, D.M.; Xia, J.; Yan, Z.; Yang, J.; Liu, Q.; Huo, H. Assessment of the economic impacts of heat waves: A case study of Nanjing, China. J. Clean. Prod. 2018, 171, 811-819. [CrossRef]

58. Hu, J.; Wen, Y.; Duan, Y.; Yan, S.; Liao, Y.; Pan, H.; Zhu, J.; Yin, P.; Cheng, J.; Jiang, H. The impact of extreme heat and heat waves on emergency ambulance dispatches due to external cause in Shenzhen, China. Environ. Pollut. 2020, 261, 114156. [CrossRef]

59. Varotsos, C.A.; Mazei, Y.A. Future Temperature Extremes Will Be More Harmful: A New Critical Factor for Improved Forecasts. Int. J. Environ. Res. Public Health 2019, 16, 4015. [CrossRef] [PubMed] 